\title{
Regulation of High-Affinity Leucine Transport in Escherichia coli
}

\author{
Robert Landick, James J. Anderson, Mary M. Mayo, Robert P. Gunsalus, \\ Penelope Mavromara, Charles J. Daniels, and Dale L. Oxender \\ Department of Biological Chemistry, University of Michigan, Ann Arbor, Michigan 48109
}

\begin{abstract}
Leucine is transported into $\mathrm{E}$ coli by two osmotic shock-sensitive, high-affinity systems (LIV-I and leucine-specific systems) and one membrane bound, lowaffinity system (LIV-II). Expression of the high-affinity transport systems is altered by mutations in $l i v R$ and $1 s t R$, genes for negatively acting regulatory elements, and by mutations in rho, the gene for transcription termination. All four genes for high-affinity leucine transport ( $l i v J, l i v K, l i v H$, and liv $G$ ) are closely linked and have been cloned on a plasmid vector, pOX1. Several subcloned fragments of this plasmid have been prepared and used in complementation and regulation studies. The results of these studies suggest that $l i v J$ and $l i v K$ are separated by approximately one kilobase and give a gene order of liv $J-$ liv $K$-liv $H$. livJ and liv $K$ appear to be regulated in an interdependent fashion; $l i \nu K$ is expressed maximally when the liv $J$ gene is inactivated by mutation or deletion. The results support the existence of separate promoters for the $l i v J$ and $l i v K$ genes. The effects of mutations in the rho and liv $R$ genes are additive on one another and therefore appear to be involved in independent regulatory mechanisms. Mutations in the rho gene affect both the LIV-I and leucinespecific transport systems by increasing the expression of liv $J$ and $l i v K$, genes for the LIV-specific and leucine-specific binding proteins, respectively.
\end{abstract}

Key words: leucine transport genes, cloning, regulation, rho factor

Two distinct leucine transport systems are present in E coli K12. A lowaffinity membrane-bound system (LIV-II) is osmotic shock resistant [1-4] and can be observed in membrane vesicle preparations [5]. High-affinity transport systems involving periplasmic leucine-binding proteins (LIV-and leucine-specific binding proteins) are sensitive to osmotic shock treatment [4, 6]. System LIV-I transports L-leucine, L-isoleucine, L-valine, L-threonine, and L-alanine and is absent from strains with mutations in livJ, the structural gene for the LIV-binding protein. Mutations in liv $K$, the structural gene for the leucine-specific binding protein, affect high-affinity leucine-specific transport [7]. In addition, two other loci, liv $H$ and liv $G$, are essential

James J. Anderson is now at Genex Corp., Rockville, MD 20852.

Mary M. Mayo is now at The Salk Institute, San Diego, CA 92112.

Robert P. Gunsalus is now at the Department of Biological Sciences, Stanford University, Stanford, CA 94305.

Received June 3, 1980; accepted September 18, 1980. 
for both the high-affinity leucine transport systems [8]. All four genes are clustered at minute 74 on the revised E coli linkage map [9]. The LIV-II system is weakly repressed (2-fold) by high exogenous L-leucine levels, in contrast to the more pronounced repression $(>10$-fold) observed for the high-affinity leucine transport systems [10].

Two mutations resulting in reduced regulation of high-affinity leucine transport have been characterized and map at $\min 20$ on the E coli chromosome [11]. These mutations, liv $R$ and $l s t R$, appear to code for negatively acting regulatory elements. Mutations in several other gene loci alter the activity of the high-affinity transport systems. These mutations include rho [12]; hisT, which codes for a tRNA modifying enzyme [13] ; leuS, a gene locus coding for leucyl-tRNA synthetase [14]; and $\operatorname{rel} A$, the gene coding for guanosine $5^{\prime}$-diphosphate $3^{\prime}$-diphosphate (ppGpp) synthesis [15]. These results suggest that normal leucine transport regulation involves interaction of charged or uncharged leucyl-tRNA and rho with transcription and/or translation initiation. The regulation of leucine transport appears similar to that found for the regulation of the biosynthetic operons for tryptophan, histidine, phenylalanine, and leucine [16-19] .

Recently we have cloned the entire genetic complex coding for the four known LIV-I transport genes into the plasmid vector pACYCl84 [20]. When introduced into a wild-type regulatory background, the genes on this hybrid plasmid, pOX1, are subject to regulation. In this paper we present the results of regulation studies with the cloned leucine transport genes and additional characterization of the effect of $r$ o on this regulation.

\section{METHODS}

\section{Growth Conditions}

Unless otherwise indicated, all strains were grown in MOPS minimal medium [21] with $0.2 \%$ glucose, $50 \mu \mathrm{g} / \mathrm{ml}$ thymine, L-arginine, and L-histidine, $10 \mu \mathrm{g} / \mathrm{ml}$ of L-tryptophan, and $1 \mu \mathrm{g} / \mathrm{ml}$ of L-tryptophan, and $1 \mu \mathrm{g} / \mathrm{ml}$ pyridoxine.

\section{Transport and Binding Protein Assays}

Leucine transport was assayed as described previously [11]. Binding proteins were assayed by osmotic treatment of cells [6] and subjecting the concentrated shock fluids to equilibrium dialysis as described previously [4].

\section{Restriction Endonuclease Digestion, Preparation, and Ligation of Plasmid DNA}

Endonuclease digestions were performed as described by Boyer et al [22]. All enzymes were purchased from Bethesda Research Labs, Inc. (Bethesda, MD). Plasmid DNA was prepared by the cleared lysate procedure of Clewell and Helinski [23] and purified by $\mathrm{CsCl}$ gradient ultracentrifugation. Plasmid restriction fragments were isolated by electrophoresis on $0.8 \%$ agarose gels as described previously [24]. Plasmid pOX1 was constructed as described [20]. Plasmids pOX5 [29] and pOX6 were prepared by restricting pOX1 with $B g l \mathrm{II}$ and Pst I, respectively, isolating and religating the fragment containing the pACYC184 vector sequence with T4 DNA ligase. Plasmid pOX7 was prepared by isolating the $2.1 \mathrm{~kb}$ $B g l$ II fragment from pOX1 and cloning it into the Bam HI site of pBR322 as described [29] . Plasmid pOX13 was similarly prepared by cloning the $4.4 \mathrm{~kb}$ Hind III-Bam HI fragment of pOX1 into pBR322 that had been restricted with Bam $\mathrm{HI}$ and Hind III. 


\section{$\left[{ }^{3} \mathrm{H}\right]$ - Labeling and Analysis of Binding Proteins}

Cultures ( $2 \mathrm{ml}$ ) of pOX1-transformed strain AE89 (liv $R^{+} 1 s t R^{+}$liv $\left.H\right)$ were grown in MOPS minimal medium plus $0.01 \mathrm{mCi}$ of $\left[{ }^{3} \mathrm{H}\right]$-L-alanine. Shock fluids were prepared in $0.2 \mathrm{ml}$ of $0.5 \mathrm{mM} \mathrm{MgCl}_{2}$ as described [6]. Aliquots of shock fluid were electrophoresed in $11 \%$ native polyacrylamide gels as described by Laemmli [26]. The binding protein bands were excised from the gel, oxidized in a Packard Sample Oxidizer, and the tritium recovered in scintillation fluid for counting. TCA precipitates were treated similarily, and the levels of binding proteins were calculated as the percent of total TCA precipitable counts in the binding protein bands.

\section{Detection of Binding Proteins by Nitrocellulose Blot and Antibody Reaction}

Native gels of shock fluids were prepared as above. The electrophoresed proteins were transferred to nitrocellulose paper as described by Towbin et al [27] in a Savant electrophoretic destainer. The paper was incubated with $\left[{ }^{125} \mathrm{I}\right]$-labeled anti-LIV-binding protein antibody at $37^{\circ} \mathrm{C}$ for $4 \mathrm{~h}$ in the presence of $3 \% \mathrm{BSA}$ and $1 \%$ calf serum to prevent nonspecific adsorption. After excess antibody was washed off with PBS, the nitrocellulose paper was dried and autoradiographed.

\section{Transposon tn5 Insertions}

Transposon tn 5 was transferred to the pOX1 plasmid by infecting a pOX1 plasmidcontaining strain with a temperature sensitive lambda phage carrying the $\operatorname{tn} 5 \operatorname{transposon}$. Infected cells were plated on Luria broth plates containing kanamycin $(20 \mu \mathrm{g} / \mathrm{ml})$ and tetracycline $(10 \mu \mathrm{g} / \mathrm{ml})$ and incubated at $37^{\circ} \mathrm{C}$. Resistant colonies were scraped off the plates and used for plasmid DNA preparation. This plasmid preparation was used to transform strain AE205 (livH livJ). Cells carrying a plasmid with a tn5 insertion were selected on kanamycin tetracycline Luria broth plates. Those colonies also resistant to $40 \mu \mathrm{g} / \mathrm{ml}$ L-valine (phenotype of LIV-I transport mutant) were selected on minimal media plates and then screened for synthesis of LIV-binding protein and high-affinity LIV-I transport. Colonies that produced LIV-binding protein but were defective in high-affinity L-leucine transport contained plasmids with tn 5 insertions in livH. Colonies that did not produce LIV-binding protein and showed high-affinity uptake of L-leucine but not L-valine contained plasmids with tn 5 insertions in livJ.

\section{RESULTS}

We have previously reported cloning a $13 \mathrm{~kb}$ Eco RI fragment into the plasmid vector pACYC184 to form the pOX 1 plasmid, which was shown to complement all 4 known classes of high-affinity leucine transport mutations [20]. The leucine-specific binding protein gene has been located, and the direction of transcription was determined to be from left to right in Figure 1. [29].

\section{Structure of the LIV Transport Region}

To define the arrangement of genes in the LIV-I transport region of the pOX1 plasmid, we prepared several plasmids containing a subset of the pOX1 DNA sequence. Figure 1 shows the portions of the $13 \mathrm{~kb}$ Eco RI fragment contained by each of the subcloned plasmids. The deleted plasmids pOX5 and pOX6 contain the entire pACYCl84 vector sequence; $\mathrm{pOX} 7$ and pOX13 were prepared by cloning the respective restriction fragments shown in Figure 1 into the plasmid vector pBR322 [25]. The ability of these plasmids to complement previously characterized high-affinity leucine transport mutants was determined by transforming the various mutants with each plasmid and measuring 


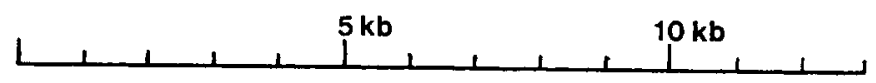

p0X13

pox7

pox6

pox5

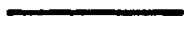

pOXI
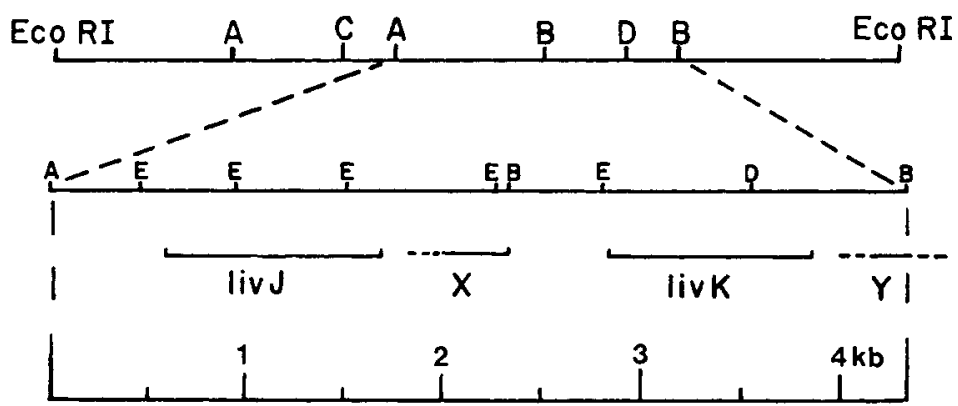

Fig. 1. Plasmids derived from pOX 1 were prepared by deleting a small restriction fragment from pOXI and religating the remaining linear strand with T4 DNA ligase (pOX5 and pOX6) or by preparing a defined restriction fragment and subcloning it into a site in pBR322 (Bam HI site for pOX7 and the Bam $\mathrm{HI}$ and Hind III sites for pOX13). These plasmids contain the sequences indicated by the solid lines. livJ is the structural gene for the LIV-binding protein; $l i v K$ is the structural gene for the leucine-specific binding protein. Restriction sites are indicated by letters. A, Pst I; B, Bgl II; C, Hind III; D, Bam HI; and E, Hinc II.

leucine transport. Where appropriate an increase in the synthesis of the binding proteins was detected directly by polyacrylamide gel electrophoresis of shock fluids from transformed strains. The results of these complementation tests, together with the previously published pOXI results [20], are presented in Table I. We have previously shown by DNA sequencing that livK, the gene for the leucine-specific binding protein, begins 500 bases to the right of the left $B g l$ II site shown in Figure 1 and is transcribed in the rightward direction [29]. Since pOX13 and not pOX7 complements a mutation in livJ, the gene for the $L I V$-binding protein, we conclude that liv $J$ is upstream from the livK gene. We have confirmed this result by isolating a plasmid derived from pOX 1 with a transposon $\operatorname{tn} 5$ inserted in the livJ gene. This plasmid, pOX1::tn $5 l i v J 24$, contains a tn 5 insertion approximately 500 bases downstream from the right-hand $P s t \mathrm{I}$ site, as shown in Figure 2. A livJ mutant transformed with pOX $1:: \operatorname{tn} 5 / i v J 24$ produced no protein cross-reactive with antibody to the LIV-binding protein. Therefore this tn 5 insertion must occur early in the liv $J$ gene. Iliv $J$ is over $1 \mathrm{~kb}$ in length (the molecular weight of the LIV-binding protein is 37,500 ) and is intact on the pOX6 plasmid, which is deleted between the Pst I sites. Therefore, liv $J$ must also be transcribed from left to right, as shown in Figure 1. This position of 

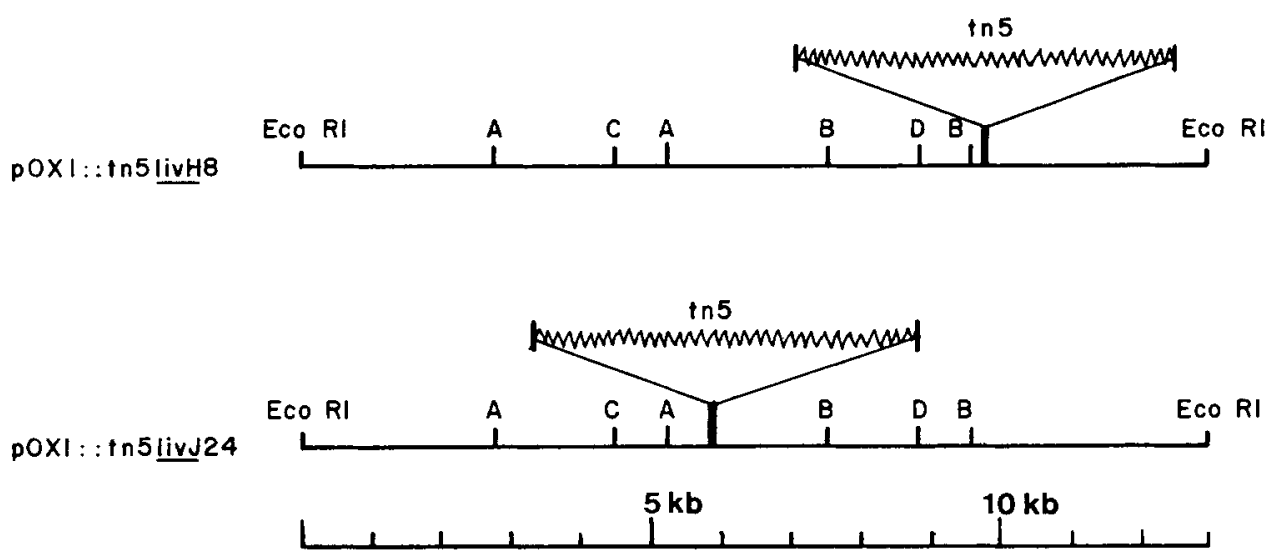

Fig. 2. Tn5 insertions were isolated as described in Methods. The insertions were mapped by restriction enzyme digestion of inserted plasmids and comparison of the products with the known sites in pOX1 and $\operatorname{tn} 5$. pOX $1:: \operatorname{tn} 5$ liv $H 8$ was mapped with restriction enzymes Hind III, Sal I, and $B g l$ II. pOX1::tn5livJ 24 was mapped with restriction enzymes Hind III, Sal I, and Pst I.

the liv $J$ gene leaves a minimum of one kilobase from its end to the beginning of the livK gene, a distance sufficient to code for an additional protein of up to 35,000 daltons. This region is represented by $\mathrm{X}$ in Figure 1 .

A comparison of Table I with the plasmid fragments in Figure 1 also reveals that liv $H$ must lie at least in part to the left of the right $B g l$ II site. A tn5 transposon insertion in the livH gene of pOX1 was isolated which confirms this result. As shown in Figure 2, pOX1::tn5livH8 contains a tn5 insertion approximately 100 bases downstream from the left $B g l$ II site. We conclude that this region, represented by $\mathrm{Y}$ in Figure 1, is most likely the liv $H$ gene.

Recently we have obtained preliminary DNA sequence information which confirms the gene map shown in Figure 1. The liv $J$ gene has been located as predicted above. Upstream from livK is a 500-base AT-rich region that contains numerous nonsense codons in all three reading frames and is likely to be a spacer or regulatory region for the liv $K$ gene. Around the right $B g l$ II site we have located a sequence that contains a single reading frame not interrupted by nonsense codons. When translated, this sequence codes for a basic cysteinerich protein. We expect the livH protein to be both basic and cysteine-rich by analogy to the his $P$ protein described by Ames and co-workers for high-affinity histidine transport in $S$ typhimurium [30, 31]. A similar basic cysteine-rich coding region has been found in region $\mathrm{X}$. These DNA sequences will be published elsewhere when completed.

\section{Regulation of Plasmid Transport Genes}

We have previously shown that the amplified leucine transport present in pOX1 transformed strains is regulated by the concentration of L-leucine in the medium [20] . To determine if DNA sequences involved in the regulation of both leucine-binding protein genes are present in pOX1 and its derivatives, we have assayed the level of the LIV-and leucine-specific binding proteins produced when transformed strains were grown in the presence and absence of leucine. The results of these experiments are shown in Table II. 
TABLE I. Complementation of Known LIV Genes by pOX Plasmids

\begin{tabular}{lcccc}
\hline Plasmid & livja & liv $K^{a}$ & livH & liv $G^{b}$ \\
\hline pOX1 & + & + & + & + \\
pOX5 & + & - & - & - \\
pOX6 & + & + & + & $\mathrm{X}^{\mathrm{c}}$ \\
pOX7 & - & + & - & - \\
pOX13 & + & - & - & - \\
\hline
\end{tabular}

a Binding protein gene complementation was assayed by detection of gene products on polyacrylamide gels.

$\mathrm{b} l i v H$ and liv $G$ complementation was assayed by leucine transport measurements in plasmid-transformed mutant strains.

cX, not determined.

TABLE II. Regulation of Binding Protein Synthesis in Transformed Strains

\begin{tabular}{|c|c|c|c|c|c|}
\hline \multirow[b]{3}{*}{ Strain } & \multirow[b]{3}{*}{ Plasmid } & \multicolumn{2}{|c|}{ Binding protein synthesis ${ }^{a}$} & & \\
\hline & & \multicolumn{2}{|c|}{ LIV } & \multicolumn{2}{|c|}{ LS } \\
\hline & & No L-leucine & +L-leucine & No L-leucine & +L-leucine \\
\hline \multirow[t]{7}{*}{$\mathrm{AE} 89^{\mathrm{b}}$} & - & 7.9 & 3.1 & 2.8 & 1.0 \\
\hline & pBR322 & 5.0 & 3.1 & 2.0 & 0.8 \\
\hline & pOX 1 & 80 & 51 & 3.0 & 1.0 \\
\hline & pOX5 & 74 & 55 & 2.0 & 0.8 \\
\hline & pOX6 & 89 & 47 & 3.5 & 1.4 \\
\hline & poX7 & 5.6 & 3.1 & 23 & 15 \\
\hline & pOX13 & 86 & 25 & 2.7 & 1.0 \\
\hline
\end{tabular}

${ }^{a}\left[{ }^{3} \mathrm{H}\right]-\mathrm{L}$-alanine counts in binding protein $/ \operatorname{total}\left[{ }^{3} \mathrm{H}\right]$-L-alanine counts in TCA precipitate of osmotic shock fluid $\times 100$. See Methods for experimental protocol.

bStrain AE89 is liv $R^{+} l s t R^{+} l i v H^{-}$.

Interestingly, while plasmid-bearing strains show an amplification in the level of LIV-

binding protein, no concomitant rise in leucine-specific binding protein synthesis is evident. Only when the liv $J$ gene is defective or absent, as in the pOX7 plasmid, does the livK gene show amplified expression. In the pOX7 plasmid, this amplified expression is still regulated by leucine. In all plasmids examined, significant regulation of the respective leucinebinding protein synthesis was observed. These results suggest that the relevant regulatory sequences are present on these plasmids. In particular, a regulatory region for livK must be present in the 500 bases preceding the beginning of the livK gene in pOX7. Similarly, a regulatory region for $l i v J$ must be present in the 500 bases preceding the beginning of the liv $J$ gene in pOX6. The lowered efficiency of regulation seen in the transformed strains may be caused by the amplified regulatory sequences, which could saturate the available regulatory components. These results support some degree of interdependent yet separate regulation for liv $J$ and $l i v K$ gene expression. 
TABLE III. Kinetic Constants for LIV Transport and Leucine-Binding Activities in Binding Protein Mutants

\begin{tabular}{|c|c|c|c|c|c|c|c|c|c|}
\hline \multirow[b]{3}{*}{ Strain } & \multirow[b]{3}{*}{ Genotype } & \multicolumn{6}{|c|}{ LIV uptakea } & \multirow{2}{*}{\multicolumn{2}{|c|}{$\begin{array}{l}\text { L-leucine binding activity } \\
\mathrm{pmole} / \mathrm{mg} \text { protein }\end{array}$}} \\
\hline & & \multicolumn{2}{|c|}{ L-leucine } & \multicolumn{2}{|c|}{ L-isoleucine } & \multicolumn{2}{|c|}{ L-valine } & & \\
\hline & & $\overline{\mathrm{K}_{\mathrm{m}}}$ & $\mathrm{V}_{\max }$ & $\mathrm{K}_{\mathrm{m}}$ & $\mathrm{V}_{\max }$ & $\mathrm{K}_{\mathrm{m}}$ & $\mathrm{V}_{\max }$ & $L I V \cdot B P^{b}$ & $L S-B P^{b}$ \\
\hline AE 84 & $\operatorname{liv} R$ & 0.6 & 8.3 & 0.25 & 4.3 & 0.22 & 4.2 & 660 & 163 \\
\hline AE 840102 & $\operatorname{liv} R \operatorname{liv} J$ & 0.8 & 7.7 & $\mathrm{ND}^{\mathrm{c}}$ & ND & ND & ND & 34 & 315 \\
\hline $\mathrm{AE} 84084$ & liv $R$ livK & ND & ND & ND & ND & $\mathrm{ND}$ & ND & 731 & 0 \\
\hline
\end{tabular}

${ }^{a}$ All strains grown in MOPS minimal medium without leucine and harvested during log phase growth. $\mathrm{K}_{\mathrm{m}}$ is given in $\mu \mathrm{M} ; \mathrm{V}_{\max }$ in $\mathrm{nM} /$ min per $\mathrm{mg}$ dry cell wt.

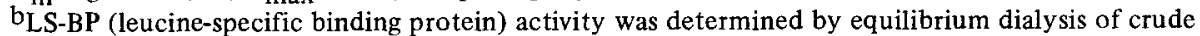
osmotic shock fluids [6] in $2.5 \mu \mathrm{M}\left[{ }^{3} \mathrm{H}\right]$-L-leucine $+200 \mu \mathrm{M}$ L-isoleucine. LIV-BP activity was calculated as activity in $2.5 \mu \mathrm{M}\left[{ }^{3} \mathrm{H}\right]$-L-leucine minus LS-BP activity.

cND, not detectable.

\section{Synthesis of Leucine-Specific Binding Protein}

The interdependent regulation of liv $J$ and $l i v K$ expression in the plasmids led us to examine the level of leucine-specific binding protein production in non-transformed strains that were defective in livJ, the LIV-binding protein gene. As shown in Table III, the uptakes of L-isoleucine and L-valine, substrates for LIV-binding protein-mediated transport, are not detectable in strain AE840102, which lacks the LIV-binding protein. LLeucine transport, however, is virtually unaffected. That this is due to an increase in leucine-specific binding protein synthesis resulting in an increase in leucine-specific transport is evident from measurements of the level of the binding proteins by equilibrium dialysis of crude shock fluids. While the amount of LIV-binding protein is 20 -fold less in strain AE840102 than that in strain AE84, the leucine-specific binding protein is amplified 2-fold.

Mutation of livK in strain AE84084 results in a slight increase in LIV-binding protein activity, which is also consistent with compensatory regulation of the two binding protein genes. The low levels of L-isoleucine and L-valine uptake in strain AE84084 are probably due to a polar effect of a Mu insertion in livK on the expression of the downstream liv $H$ gene.

\section{Rho-Dependent Regulation Is Independent of liv $R$ Regulation}

It is now well established that mutations in the gene for transcription termination, $r h o$, cause derepression of high-affinity leucine transport [12]. This phenotype is similar to that produced by the livR mutation. We wondered, therefore, whether the two effects were part.of the same regulatory mechanism or, alternatively, if the rho effect could still be observed in liv $R$ strains already derepressed for leucine transport. To answer this question, we prepared strain AE141 (livR ilv:: $\operatorname{tn} 10$ ) by transduction of the livR strain AE84 with $\mathrm{P} 1$ phage carrying a transposon tn 10 insertion in $i l v$. Since the $r h o$ gene is $85 \%$ linked to the ilv locus, we were able to introduce a rho201 mutation into strain AE141 by transducing it with a P1 phage grown on a rho201 ilv ${ }^{+}$strain (kindly provided by J. Beckwith) and then selecting for $i l v^{+}$colonies. As shown in Table IV, leucine uptake was increased 
over $400 \%$ when rho was present in this strain background. On the basis of this result, it is unlikely that rho exerts its effect on leucine transport by altering expression of the livR gene...Thus we conclude that rho-dependent termination is involved in leucine transport regulation in a manner independent of liv $R$ repression.

\section{Rho Affects the Expression of Both livJ and livK}

We previously suggested that the rho-dependent effect on high-affinity leucine transport results from a rho-dependent termination in transcription attenuation of LIV-I transport gene expression [12]. It is also possible that derepression of LIV-I genes occurs because a termination upstream from one or more of the genes is relieved by mutations in rho. In the latter case, one might expect liv $K$ expression to be more sensitive to rho mutations than the expression of $l i v J$, since $l i v K$ is clearly the downstream gene. To assess this possibility, we assayed binding protein synthesis by preparing crude shock fluids of strain X8605 and X8605rho201. The strain X8605 background has previously shown a reduced rho effect in contrast to the effect found in our own strains (Table IV). We therefore expected strain X8605 shock fluids to show corresponding reduced binding protein levels. These shock fluids were electrophoresed on polyacrylamide gels and transferred to nitrocellulose paper as described in Methods. Table $\mathrm{V}$ shows the results of these assays.

TABLE IV. Leucine Transport in liv $R$ rho Double Mutants

\begin{tabular}{|c|c|c|}
\hline Strain & Genotype & Uptake \\
\hline AE141 & livR ilv:: $\operatorname{tn} 10$ & 0.27 \\
\hline $\mathrm{AE} 141: \mathrm{P} 1(\text { rho } 201)^{b}$ & live rho 201 & 1.23 \\
\hline
\end{tabular}

${ }^{\text {a }}$ Expressed in $\mathrm{nM} / \mathrm{min}$ per $\mathrm{mg}$ dry cell wt at a $\mathbf{L}$-leucine concentration of $0.1 \mu \mathrm{M}$. Cells were grown in MOPS minimal medium without leucine.

bStrain AE141 was transduced with P1 phage grown on strain X8605 rho201 ilv ${ }^{+}$and selected for $i l v^{+}(85 \%$ linked to $r h o)$. The uptake shown is the average of that obtained for four independent isolates showing elevated transport.

TABLE V. Effect of the rho 201 Mutation on the Synthesis of LIV-and Leucine-Specific Binding Proteins

\begin{tabular}{|c|c|c|c|c|}
\hline \multirow[b]{2}{*}{ Strain } & \multicolumn{2}{|c|}{ LIV-binding protein ${ }^{a}$} & \multicolumn{2}{|c|}{ LS binding protein ${ }^{a}$} \\
\hline & - L-Leucine ${ }^{b}$ & + L-Leucine & -L-Leucine & +L-Leucine \\
\hline X8605 & 100 & 25 & $\mathrm{ND}^{\mathrm{c}}$ & $\mathrm{ND}$ \\
\hline X8605rho201 & 140 & 120 & 7 & 7 \\
\hline
\end{tabular}

a LIV- and leucine-specific binding protein synthesis was detected by the antibody nitrocellulose blot method described in Methods. Synthesis was quantitated by determining the amount of $\left[{ }^{125} I\right]$-antibody bound by each band from densitometer tracings of the autoradiographs. It is expressed as the percent relative to LIV-binding protein synthesized by strain X8605 grown without L-leucine after correcting for total protein loaded on the gel.

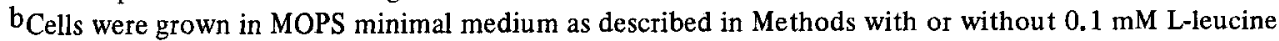
$(13 \mu \mathrm{g} / \mathrm{ml})$ and harvested in mid-log phase.

cND, not detectable. 
Shock fluid from the rho mutant, strain X8605rho201, contains an elevated concentration of LIV-binding protein relative to shock fluid from the wild-type strain X8605. The leucine-specific binding protein was not detected in shock fluid from strain X8605 but was clearly present in shock fluid from strain X8605rho201. Synthesis of neither binding protein was sensitive to regulation by external L-leucine when the rho201 lesion was present. These results clearly demonstrate that the expression of both binding protein genes is sensitive to a defective rho termination factor.

\section{DISCUSSION}

Previous work in several laboratories has led to the general observation that the level of high-affinity transport can be correlated with the concentration of specific periplasmic binding proteins for a given transport system [10]. The regulation of synthesis of the LIVand leucine-specific binding proteins is a prime determinant, therefore, in controlling the level of high-affinity leucine transport in E coli.

In this paper we have shown that liv $J$ and $l i v K$, genes for the LIV- and leucinespecific binding proteins, respectively, are separated by approximately $1 \mathrm{~kb}$ and are capable of independent expression and regulation. Both genes are transcribed in the same direction. It has been shown that transcription and translation of the upstream liv $J$ gene have a definite inhibitory effect on expression of the downstream liv $K$ gene. The magnitude of this inhibition is variable. In the X8605 strain background, no detectable leucine-specific binding protein is produced unless a rho lesion is introduced. This result may explain reports by other workers who have not observed leucine-specific uptake in certain $\mathrm{E}$ coli strains [32]. The significant levels of leucine-specific binding protein observed in our laboratory may be due to a high basal level of expression of the livK gene in our $\mathrm{E}$ coli strains.

As shown by the data in Tables II and III, the expression of livK may be further stimulated when the liv $J$ gene is mutated or deleted. This result is observed whether livK is in the chromosome or carried on a plasmid. Several explanations for this phenomenon are possible, but the data presented in this paper suggest that the 500 base pair non-coding region directly in front of the livK gene may contain an independent promoter that ordinarily is inactive but that can be activated in response to mutations or other events that reduce liv $J$ expression. Several lines of evidence suggest that this explanation is likely. First, it is clear from the results in Table $V$ that the rho effect cannot be explained solely on the basis of increased read-through of the downstream livK since liv $J$ is also affected. Thus it appears that rho can operate in regulatory regions preceding both the liv $J$ and liv $K$ genes. Second, the expression of livK is either unaffected or slightly elevated on the pOX1::tn5liv 24 plasmid, which contains the $5.5 \mathrm{~kb}$ tn 5 transposon inserted in the liv $J$ gene. It is unlikely that RNA polymerase, which initiates transcription at a promoter in front of liv $J$, would successfully transcribe the entire tn 5 sequence and continue through to the $l i v K$ gene. While transcription of the liv $K$ gene might initiate at a promoter within the $\operatorname{tn} 5$ transposon, we consider it more probable that the liv $K$ gene has a separate promoter. Third, the expression of the liv $K$ gene on the pOX7 plasmid is still regulated by L-leucine. The effect of the regulatory mutations liv $R$ and $l s t R$ also support this interpretation. Anderson and co-workers have shown that $l s t R$ leads to a dramatic derepression of leucine-specific binding protein synthesis, whereas liv $R$ leads primarily to an increase in the LIV-binding protein [11]. Both of these lesions map at min 20 on the E coli linkage map. Since these mutations complement each other genetically, they appear to represent 
independent negatively acting regulatory elements. The fact that they differentially affect liv $J$ and livK expression stongly suggests that the liv $R$ gene product acts as a promoter in front of livJ, and that the $l s t R$ gene product acts as promoter in front of livK. Finally, in support of a separate regulatory region for the livK gene, the 500 base pair AT-rich region, immediately upstream of the livK gene, contains the sequence TGTTTGTCTATCAATAAATTCGGAATATTATCTGTTC approximately 250 bases upstream from the liv $K$ start codon. This sequence corresponds closely to the conserved elements (underlined) or previously identified RNA polymerase promoters [33].

In developing a model for leucine transport regulation, the effects of leucyl-tRNA, rho factor, and ppGpp must be considered. With the exception of rho factor, we do not know whether the other regulatory elements alter the expression of only one, or both binding protein genes. In addition, the derepressing effects of mutations hisT and leuSl may be due either to negative regulation by leucyl-tRNA or to a positive effect of uncharged tRNAleu.

Our present understanding of the regulation of high-affinity leucine transport is presented in Figure 3. This is represented schematically as a working model, and is not intended to represent precisely the interactions of the various regulatory factors. We suggest that two regulatory loci are involved. The first, in front of the livJ gene, ordinarily allows high-efficiency transcription of liv $J$. Regulation at the liv $J$ promoter is accomplished by the liv $R$ gene product, a negative effector for liv $J$ gene expression. In addition, transcription termination factor rho and tRNA ${ }^{\text {leu }}$ also regulate $i v J$ expression [10]. As shown in Figure 3, we suggest that a second regulatory site, most likely including a second promoter, exists directly in front of $l i v K$. The product of $l s t R$ apparently acts at the livK promoter in a manner similar to the action of liv $R$ gene product at the liv $J$ promoter.

Finally, we wish to point out the evolutionary implications of this model. On the basis of amino acid sequences obtained by Dr. Ovchinnikov and colleagues [34; personal communication] and our own DNA sequencing studies it is clear that liv $J$ and liv $K$ have evolved from a common ancestral gene by gene duplication. The amino acid sequence of the two binding proteins is approximately $80 \%$ conserved. Regions $\mathrm{X}$ and $\mathrm{Y}$ show similar-

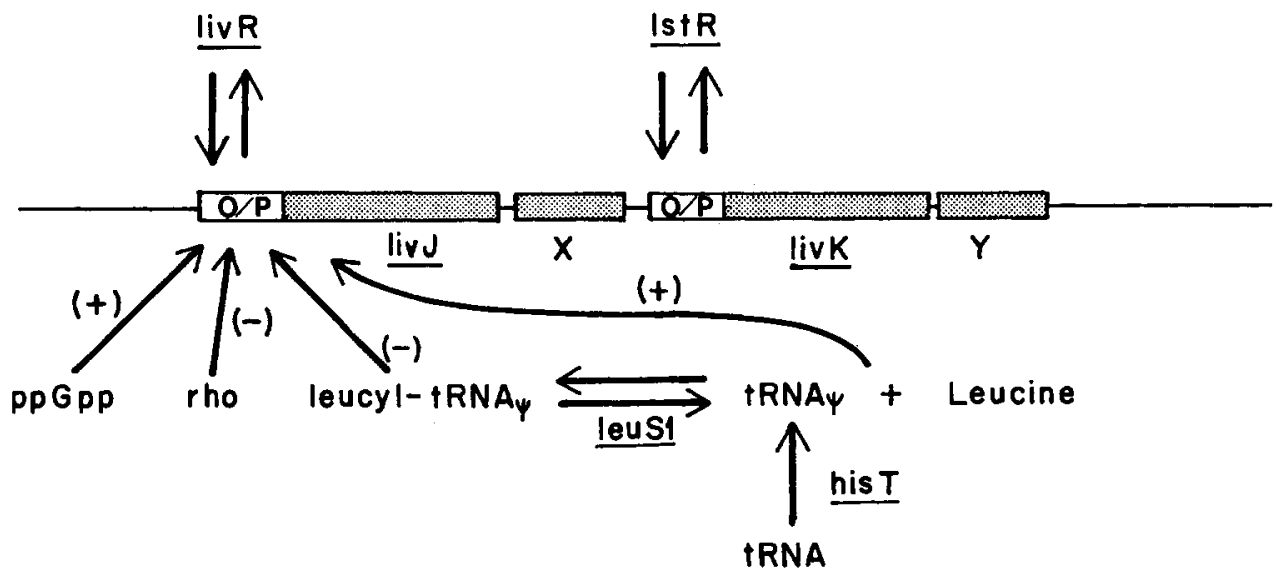

Fig. 3. Model of leucine transport regulation in Escherichia coli. 
ities in size and position, suggesting that this duplication involved a larger region than the binding protein gene itself. If the regulatory regions in front of livK and livJ were included in this duplication, then these regions have diverged from a common ancestor, since the two genes are now regulated differently. Additional sequence analysis will provide more information on the evolutionary relationships of the regulatory regions and mechanisms.

\section{REFERENCES}

1. Anderson JJ, Oxender DL: J Bacteriol 136:168, 1978.

2. Oxender DL, Anderson JJ, Mayo MM, Quay SC: J Supramol Struct 6:419, 1977.

3. Oxender DL: In Manson LA (ed): "Biomembranes." New York: Plenum Press, 1975, vol 5, p 25.

4. Oxender DL, Quay SC: In Korn ED (ed): "Methods in Membrane Biology." New York: Plenum Press, 1976, vol 6, p 183.

5. Kaback HR: Methods Enzymol 22:99, 1971.

6. Neu HC, Heppel LA: J Biol Chem 240:3685, 1965.

7. Anderson JJ, Oxender DL: J Bacteriol 130:384, 1977.

8. Mayo MM: Dissertation University of Michigan Ann Arbor, Michigan, 1979.

9. Bachman BJ, Low KB, Taylor AL: Bacteriol Rev 40:116, 1966.

10. Quay SC, Oxender DL: In Goldberger (ed) "Biological Regulation and Development." New York: Plenum Press, 1980, vol 2, p 413.

11. Anderson JJ, Quay SC, Oxender DL: J Bacteriol 126:80, 1976.

12. Quay SC, Oxender DL: J Bacteriol 130:1024, 1977.

13. Quay SC, Lawther RP, Hatfield GW, Oxender DL: J Bacteriol 134:683, 1978.

14. Quay SC, Kline EC, Oxender DL: Proc Natl Acad Sci USA 72:3921, 1975.

15. Quay SC, Oxender DL: J Bacteriol 137:1059, 1979.

16. Lee F, Yanofsky C: Proc Natl Acad Sci USA 74:4365, 1977.

17. Johnston HM, Barnes WM, Chumley FG, Bossi L, Roth JR: Proc Natl Acad Sci USA 77:508, 1980.

18. Zurawski G, Brown K, Killingly D, Yanofsky C: Proc Natl Acad Sci USA 75:4271, 1978.

19. Keller EB, Calvo JM: Proc Natl Acad Sci USA 76:6186, 1979.

20. Oxender DL, Anderson JJ, Daniels CJ, Landick R, Gunsalus RP, Zurawski G, Selker E, Yanofsky C: Proc Natl Acad Sci USA 77:1412, 1980.

21. Neidhardt FC, Block PL, Smith DF: J Bacteriol 119:736, 1974.

22. Green PJ, Heynecker HL, Bolivar F, Rodriquez RL, Betlach MC, Covarrubias AA, Backman K, Russel DJ, Tait R, Boyer HW: Nucleic Acids Res 5:2373, 1978.

23. Clewell DB, Helinski DR: Proc Natl Acad Sci USA 62:1159, 1969.

24. Selker E, Brown K, Yanofsky C: J Bacteriol 129:338, 1977.

25. Bolivar F, Rodriquez RL, Greene PJ, Betlach MC, Heynecker HL, Boyer HW: Gene 2:95, 1977.

26. Laemmli UK: Nature 227:680, 1970.

27. Towbin H, Staehelin T, Gordon J: Proc Natl Acad Sci USA 79:4350, 1979.

28. Daniels CJ, Anderson JJ, Landick R, Oxender DL: J Supramol Struct (in press).

29. Oxender DL, Anderson JJ, Daniels CJ, Landick R, Gunsalus RP, Zurawski G, Yanofsky C: Proc Natl Acad Sci USA 77:2005, 1980.

30. Ames GF-L, Spudich EN: Proc Natl Acad Sci USA 73:1187, 1977.

31. Ames GF-L, Nikaido K: Proc Natl Acad Sci USA 75:5447, 1978.

32. Yamamoto I, Ohki M, Anraku Y: J Bacteriol 138:24, 1979.

33. Rosenberg M, Court D: Annu Rev Genet 13:319, 1979.

34. Ovchinnikov YA, Aldanova NA, Grinkevich VA, Arzamazova NM, Moroz IN, Nazimov IV: Bioorg Chem USSR 3:564, 1977. 